\title{
Pathophysiology, Evaluation, and Management of Metabolic Alkalosis
}

\author{
Mohammad Tinawi ${ }^{1,2}$ \\ 1. Nephrology, Nephrology Specialists, P.C, Munster, USA 2. Medicine, Indiana University School of Medicine \\ Northwest, Gary, USA
}

Corresponding author: Mohammad Tinawi, mtinawi@gmail.com

\begin{abstract}
Metabolic alkalosis is an increase in blood $\mathrm{pH}$ to $>7.45$ due to a primary increase in serum bicarbonate $\left(\mathrm{HCO}_{3}{ }^{-}\right)$. Metabolic alkalosis results from alkali accumulation or acid loss, and it is associated with a secondary increase in carbon dioxide arterial pressure $\left(\mathrm{P}_{\mathrm{a}} \mathrm{CO}_{2}\right)$. Metabolic alkalosis is a common acid-base disorder, especially in critically ill patients. The pathogenesis of chronic metabolic alkalosis includes two derangements, generation of metabolic alkalosis via gain of alkali or loss of acid and maintenance of metabolic alkalosis by increased tubular $\mathrm{HCO}_{3}{ }^{-}$reabsorption (failure of the kidneys to excrete excess alkali). Metabolic alkalosis is the most common acid-base disorder in hospitalized patients, particularly in the surgical critical care unit. Mortality increases as $\mathrm{pH}$ increases.
\end{abstract}

Categories: Family/General Practice, Internal Medicine, Nephrology

Keywords: metabolic alkalosis, acid-base disorders, acid-base physiology, alkalemia

\section{Introduction And Background}

The focus of this review article is the pathophysiology of metabolic alkalosis, as well as its causes, diagnosis, and management. The PubMed database was searched for relevant basic science and clinical articles in addition to the leading journals in nephrology, endocrinology, critical care, and internal medicine. The articles reviewed included clinical trials, comprehensive reviews, and case studies deemed of clinical significance. Chapters from the major textbooks were reviewed as well.

Intracellular $\mathrm{pH}$ is 7.0-7.30 while normal arterial blood $\mathrm{pH}$ is 7.35-7.45 [1-2]. Arterial blood $\mathrm{pH}$ is kept in a narrow range due to renal and respiratory regulations and multiple intracellular and extracellular buffers. Arterial blood gases (ABGs) are required to ascertain the diagnosis of acid-base disorders. For example, high serum $\mathrm{HCO}^{-}$can result from metabolic alkalosis or metabolic compensation for respiratory acidosis. A high blood $\mathrm{pH}>7.45$, i.e., low arterial blood hydrogen $\left(\mathrm{H}^{+}\right)$defines alkalemia, if serum $\mathrm{HCO}^{-}$is high, the alkalemia is due to metabolic alkalosis, while if carbon dioxide arterial pressure $\left(\mathrm{P}_{\mathrm{a}} \mathrm{CO}_{2}\right)$ is low, the alkalemia

Review began 01/15/2021 Review ended 01/16/2021 Published 01/21/2021

\section{○ Copyright 2021}

Tinawi. This is an open access article distributed under the terms of the Creative Commons Attribution License CC-BY 4.0., which permits unrestricted use, distribution, and reproduction in any medium, provided the original author and source are credited. is due to respiratory alkalosis. In metabolic alkalosis, arterial $\mathrm{HCO}^{-}$is $>28 \mathrm{mmol} / 1$ and venous total $\mathrm{CO}_{2}$ is

$>30 \mathrm{mmol} / \mathrm{l}$ [3]. A gain of alkali or loss of acid leads to metabolic alkalosis. If serum $\mathrm{HCO}^{-}{ }^{-}$is high and $\mathrm{P}_{\mathrm{a}} \mathrm{CO}_{2}$ is low, the alkalemia is due to a mixed acid-base disorder, namely, metabolic alkalosis and respiratory

alkalosis [4]. A simple acid-base disorder is due to a change in either $\mathrm{P}_{\mathrm{a}} \mathrm{CO}_{2}$ or serum $\mathrm{HCO}^{-}$with appropriate metabolic or respiratory compensation, respectively. A mixed acid-base disorder is the presence of two or three acid-base disorders simultaneously [5]. Metabolic alkalosis is usually accompanied by

hypokalemia and hypochloremia. This reduction in chloride $\left(\mathrm{Cl}^{-}\right)$is not accompanied by hyponatremia [6] Serum anion gap (AG) is usually slightly elevated in metabolic alkalosis due to an increase in the net negative charges of plasma proteins [7]. To summarize, in simple acid-base disorders,

serum $\mathrm{HCO}^{-}$and $\mathrm{P}_{\mathrm{a}} \mathrm{CO}_{2}$ move in the same direction (both are up in metabolic alkalosis and respiratory acidosis and both are down in metabolic acidosis and respiratory alkalosis). In mixed acid-base disorder, serum $\mathrm{HCO}^{-}$and $\mathrm{P}_{\mathrm{a}} \mathrm{CO}_{2}$ move in the opposite direction.

The next step after diagnosing metabolic alkalosis is the determination of respiratory compensation. For every $1 \mathrm{mmol} / \mathrm{l}$ rise in $\mathrm{HCO3}^{-}$above $24 \mathrm{mmol} / \mathrm{l}$, there is a $0.6 \mathrm{mmHg}$ rise in $\mathrm{P}_{\mathrm{a}} \mathrm{CO}_{2}$ as per the following equation:

$\mathrm{P}_{\mathrm{a}} \mathrm{CO}_{2}(\mathrm{mmHg})=40+0.6 \times\left(\mathrm{HCO}^{-}-24 \mathrm{mmol} / \mathrm{l}\right)$

For example, if $\mathrm{HCO}^{-}$is $40 \mathrm{mmol} / \mathrm{l}$, the rise in $\mathrm{HCO}^{-}$is $40-24=16 \mathrm{mmol} / \mathrm{l}$, the rise in $\mathrm{P}_{\mathrm{a}} \mathrm{CO}_{2}$ is $0.6 \times 16=$ $9.6 \mathrm{mmHg}$, and the expected $\mathrm{P}_{\mathrm{a}} \mathrm{CO}_{2}$ is $40+9.6$ or approximately $50 \mathrm{mmHg}$. A quick way to determine 
$\mathrm{P}_{\mathrm{a}} \mathrm{CO}_{2}$ is by adding 15 to $\mathrm{HCO}^{-}$[8]. Metabolic alkalosis is accompanied by alveolar hypoventilation, which takes minutes to hours to occur [9]. Respiratory compensation usually does not result in complete $\mathrm{pH}$ normalization [9]. In metabolic alkalosis, $\mathrm{P}_{\mathrm{a}} \mathrm{CO}_{2}$ is rarely over $55 \mathrm{mmHg}$. A pH that is close to the normal range may indicate a mixed acid-base disorder, namely, metabolic alkalosis and respiratory acidosis [10]. An example of such disorder is a patient with chronic respiratory acidosis due to chronic obstructive pulmonary disease (COPD) who develops a concomitant metabolic alkalosis due to diuresis. It is helpful to remind the reader of the concept of base excess, which is routinely reported on ABGs. An ABG sample under standard (normal) conditions has a $\mathrm{pH}$ of $7.40, \mathrm{P}_{\mathrm{a}} \mathrm{CO}_{2}$ of $40 \mathrm{mmHg}$, a temperature of $37^{\circ} \mathrm{C}$, and a base excess of 0

$\mathrm{mmol} / \mathrm{l}$. Base excess is defined as the amount of strong acid in $\mathrm{mmol} / \mathrm{l}$ that needs to be added to one liter of fully oxygenated blood in vitro to return an ABG sample to the above-defined standard conditions [11]. Base excess is negative in metabolic acidosis and positive in metabolic alkalosis. The normal range of base excess is -2 to $+2 \mathrm{mmol} / \mathrm{l}$. For example, an $\mathrm{ABG}$ sample in a patient with severe metabolic alkalosis showed $\mathrm{pH}$ 7.55, $\mathrm{P}_{\mathrm{a}} \mathrm{CO}_{2} 49 \mathrm{mmHg}, \mathrm{HCO}^{-} 38 \mathrm{mmol} / \mathrm{l}$, and a base excess of $14 \mathrm{mmol} / \mathrm{l}$.

\section{Review \\ Incidence}

Metabolic alkalosis was the most common acid-base disorder in patients in the intensive care unit (ICU) in a large Norwegian study [12]. The study analyzed 138,523 ABGs. On admission to ICU, acidosis (metabolic and respiratory) is more common. $\mathrm{HCO}^{-}$increases over time. Alkalosis was defined as base excess $>0$ on ABGs and was found in 118,014 samples (85\%). A stricter definition of alkalosis as base excess $>2 \mathrm{mmol} / \mathrm{L}$ would have led to a lower reported incidence. Alkalosis was found as a simple or mixed acid-base disorder, including post-hypercapnic alkalosis in patients with COPD on mechanical ventilation. A prospective study by Okusawa et al. enrolled 293 general surgical patients [13]. Six ABGs were taken from each patient starting on postoperative day 0 and ending on postoperative day 7 . The vast majority of patients (87.5\%) had a normal acid-base balance preoperatively. Postoperatively, $50.5 \%$ of patients developed metabolic alkalosis. Other acid-base abnormalities were uncommon. Metabolic alkalosis persisted in 31 patients and carried a high mortality rate of $32 \%$. The administration of fresh frozen plasma (FFP) was a major cause of metabolic alkalosis postoperatively. Hodgkin et al. analyzed 13,430 ABGs obtained from hospitalized patients [14]. Metabolic alkalosis was by far the most common acid-base disorder (51\%), followed by respiratory alkalosis (29\%), then respiratory acidosis (27\%), and, finally, metabolic acidosis (12\%). The reported incidence adds to more than $100 \%$ due to the presence of mixed acid-base disorders in some patients. For example, metabolic alkalosis was simple in $70 \%$ of cases and mixed with respiratory or metabolic acidosis in the remaining $30 \%$. An earlier study by Wilson et al. in 1415 critically ill surgical patients showed that 177 (12\%) developed severe metabolic alkalosis defined as arterial $\mathrm{pH}>7.54$ [15]. More severe metabolic alkalosis was associated with higher mortality. Mortality was $41 \%$ in patients with $\mathrm{pH} 7.55-7.56,47 \%$ in patients with $\mathrm{pH}$ 7.57-7.59, $65 \%$ in patients with $\mathrm{pH} 7.60-7.64$, and $80 \%$ in patients with $\mathrm{pH}$ 7.65-7.70. A prospective study by Anderson et al. in a group of 409 medical and surgical patients showed that mortality was $48.5 \%$ in patients with $\mathrm{pH}$ $>7.60[16]$.

\section{Pathophysiology of metabolic alkalosis}

The kidneys play a major role in acid-base regulation. The three components of renal net acid excretion are ammonium (NH4+), titratable acid, and urinary $\mathrm{HCO}^{-}\left(\mathrm{U}_{\mathrm{HCO}^{-}}{ }^{-}\right.$[1-2]. All of the $\mathrm{HCO}^{-}$filtered through the glomeruli is reabsorbed under normal physiological conditions [17]. The kidneys generate new $\mathrm{HCO}^{-}$to replace the $\mathrm{HCO}^{-}$used to buffer acid in the body. About $80 \%$ of filtered $\mathrm{HCO}^{-}{ }^{-}$is absorbed by the proximal tubule (PT) while the thick ascending limb (TAL) of the loop of Henle reabsorbs 15\%. The cortical collecting duct (CCD) and the inner medullary collecting duct (IMCD) reabsorb the remaining 5\% [1]. The two cell types of the CCD are the intercalated cells, which regulate acid-base balance, and the principal cells, which, under the effect of aldosterone, secrete potassium $\left(\mathrm{K}^{+}\right)$, and reabsorb sodium $\left(\mathrm{Na}^{+}\right)$. There are two subtypes of intercalated cells (they are the functional mirror images of each other), alpha-intercalated cells, which secrete $\mathrm{H}^{+}$, and beta-intercalated cells, which secrete $\mathrm{HCO}^{-}$in exchange for $\mathrm{Cl}^{-}$and, therefore, play a role in the correction of metabolic alkalosis. The medullary collecting duct does not contain beta-intercalated cells [1-2]. In the alpha-intercalated cells, the generated $\mathrm{HCO}^{-}$exits the cell via a basolateral $\mathrm{Cl}^{-}$-

$\mathrm{HCO}^{-}$exchanger. The beta-intercalated cells generate $\mathrm{HCO}^{-}$, which exits the cell and enters the tubular lumen via an apical $\mathrm{Cl}^{-}-\mathrm{HCO}^{-}$exchanger (SLC26A4 protein \{pendrin\}) [18-19] (Figure 1). $\mathrm{HCO}^{-}$secretion in the collecting duct (CD) requires luminal $\mathrm{Cl}^{-}$and is inhibited by $\mathrm{Cl}^{-}$depletion. As we shall see, $\mathrm{Cl}^{-}$depletion is critical in the generation of metabolic alkalosis [3]. $\mathrm{Cl}^{-}$depletion increases distal $\mathrm{Na}^{+}$delivery and reabsorption, which stimulates $\mathrm{K}^{+}$and $\mathrm{H}^{+}$secretion. This explains the importance of isotonic saline solutions in the correction of metabolic alkalosis. The density of beta-intercalated cells and pendrin are both reduced in the case of hypokalemia [20]. Therefore, hypokalemia limits $\mathrm{HCO}^{-}$excretion, which explains the importance of the correction of hypokalemia in the management of metabolic alkalosis. 


\section{Cureus}
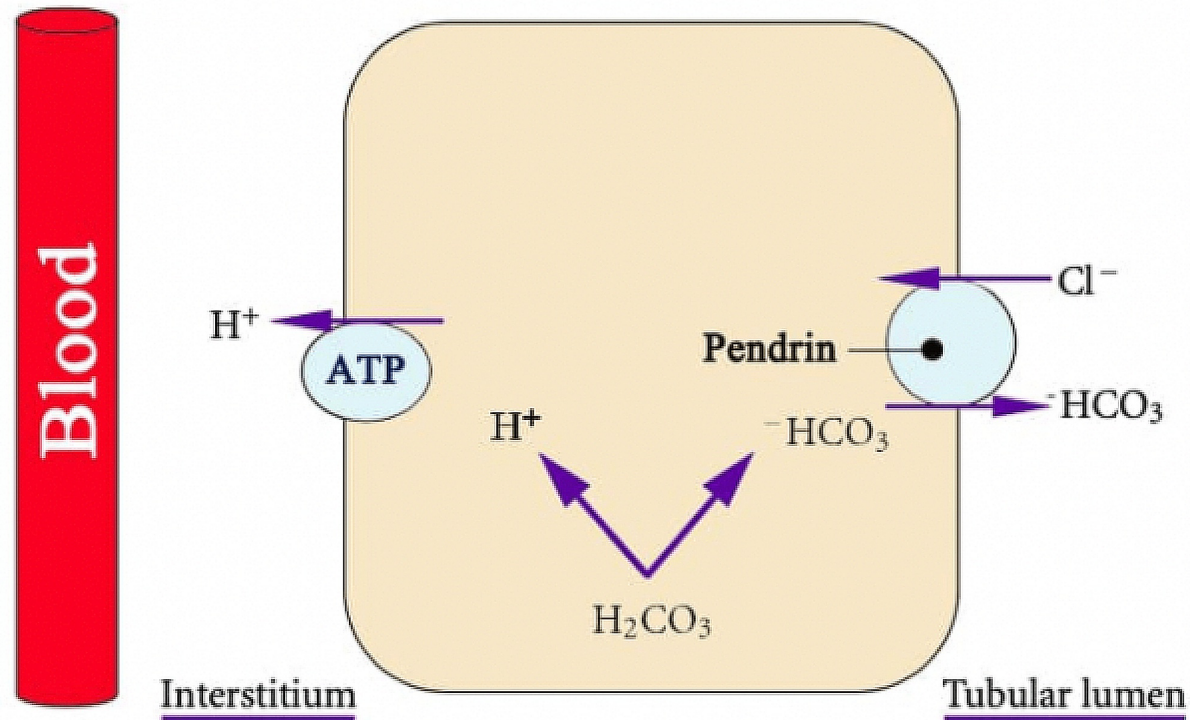

FIGURE 1: Pendrin is an apical chloride-bicarbonate exchanger in betaintercalated cells

ATP: adenosine triphosphate

Courtesy of Bruno and Valenti. J Biomed Biotechnol. 2012 [19]. This is an open-access article distributed under the Creative Commons Attribution License.

Two steps are required for metabolic alkalosis to persist. The first step is the generation of metabolic alkalosis and the second step is the maintenance of metabolic alkalosis [21]. In other words, when faced with metabolic alkalosis, one has to answer two questions. First, what is the source of the excess $\mathrm{HCO}^{-}$and second, why is the excess $\mathrm{HCO}^{-}$not excreted by the kidneys?

Generation of Metabolic Alkalosis

The generation of metabolic alkalosis is due to excess $\mathrm{HCO}^{-}$accumulation originating from endogenous or exogenous sources (Table 1).

Infusion or ingestion of $\mathrm{HCO}_{3}{ }^{-}$(e.g. $\mathrm{NaHCO}_{3}$ ) or $\mathrm{HCO}_{3}{ }^{-}$precursors (citrate, lactate, or acetate)

Hydrochloric acid $(\mathrm{HCl})$ loss as in vomiting, $\mathrm{Cr}$-rich diarrhea, or nasogastric (NG) suction

Hypokalemia leads to extracellular $\mathrm{K}^{+}$shift balanced by concomitant intracellular $\mathrm{H}^{+}$shift

Excess $\mathrm{HCO}_{3}{ }^{-}$generation by the distal tubule (due to increased $\mathrm{H}^{+}$excretion) due to increased distal delivery and subsequent absorption of $\mathrm{Na}^{+}$as in primary hyperaldosteronism, use of thiazide or loop diuretics, Gitelman and Bartter syndromes, and infusion of Na penicillin (penicillin is a poorly absorbed anion)

TABLE 1: Exogenous and endogenous mechanisms resulting in the generation of metabolic alkalosis

An example of exogenous ingestible $\mathrm{Na}^{+}$and $\mathrm{K}^{+}$alkali salts include baking soda ( $60 \mathrm{mmol} /$ teaspoon), $\mathrm{NaHCO} 3$ tablets $\left(7.8 \mathrm{mmol} / 650 \mathrm{mg}\right.$ tablet), $\mathrm{KHCO} 3$ tablets, $\mathrm{K}$ citrate tablets, Polycitra-K ${ }^{\circledR}$ and Cytra-2 ${ }^{\circledR}$. Na citrate is added as an anticoagulant to whole blood or fresh frozen plasma (FFP) and can be an important source of alkali in patients needing massive amounts of blood products as in those treated with large dose plasma exchange [9]. $\mathrm{HCO}^{-}$is generated upon complete oxidation of citrate, acetate, and lactate, all of which are organic anions. Loss of $\mathrm{HCl}$ due to vomiting or NG suctioning results in $\mathrm{HCO}^{-}$generation [8]. It is 


\section{Cureus}

useful to recall that loss of acid $\left(\mathrm{H}^{+}\right)$is equivalent to the gain of alkali $\left(\mathrm{HCO}^{-}\right)$and vice versa. Infusion of large amounts of $\mathrm{Na}$ penicillin or other $\mathrm{Na}+$ salts of nonreabsorbable anions, such as sulfate or phosphate, will generate $\mathrm{HCO}^{-}$if $\mathrm{Na}+$ reabsorption via the distal tubule is enhanced by volume depletion or mineralocorticoids (aldosterone) $[9,22]$. $\mathrm{Na}^{+}$is reabsorbed while $\mathrm{HCO}^{-}$is generated and $\mathrm{H}^{+}$is excreted as titratable acid or $\mathrm{NH}^{+}$.

Maintenance of Metabolic Alkalosis

Under normal circumstances, the kidneys excrete excess $\mathrm{HCO}^{-}$and restore the acid-base balance. Normal kidneys have an enormous ability to excrete large amounts of $\mathrm{HCO}^{-}$when ingested chronically [23]. Some advocate the use of $\mathrm{NaHCO} 3$ to improve athletic performance. When NaHCO3 was given progressively and chronically in amounts up to $400 \mathrm{mg} / \mathrm{kg}$, it was well-tolerated [23-24]. The failure of the kidneys to excrete excess $\mathrm{HCO}^{-}$is due to the presence of a mechanism that leads to the maintenance of metabolic alkalosis (Table 2).

Decreased $\mathrm{HCO}_{3}{ }^{-}$filtration due to a decline in glomerular filtration rate (GFR)

Increased $\mathrm{HCO}_{3}{ }^{-}$reabsorption in the proximal tubule due to volume (and $\mathrm{Cr}$ ) depletion

Increased $\mathrm{H}^{+}$secretion and $\mathrm{NH}_{4}{ }^{+}$excretion due to hypokalemia or increased aldosterone

TABLE 2: Mechanisms of maintenance of metabolic alkalosis

Some clinical events activate more than one mechanism for the maintenance of metabolic alkalosis. For example, volume (and $\mathrm{Cl}^{-}$) depletion decreases $\mathrm{HCO}^{-}$filtration due to a decrease in GFR, increases proximal tubular reabsorption of $\mathrm{HCO}^{-}$, and enhances $\mathrm{H}^{+}$secretion and $\mathrm{NH}^{+}$excretion due to increased aldosterone and subsequent hypokalemia [8].

Etiology of Metabolic Alkalosis

Metabolic alkalosis is divided into two major categories base on extracellular fluid (ECF) volume status, metabolic alkalosis with ECF volume contraction, and metabolic alkalosis with ECF volume expansion [8-9]. Urine chloride ( $\mathrm{Ucl}^{-}$) is helpful in differentiating the two categories. $\mathrm{Ucl}^{-}$is $<20 \mathrm{mmol} / \mathrm{l}$ in ECF volume contraction and $\mathrm{Ucl}^{-} \geqslant 20 \mathrm{mmol} / \mathrm{l}$ in ECF volume expansion (Table 3). Contraction alkalosis occurs whenever there is ECF volume depletion (contraction) associated with a fixed amount of $\mathrm{HCO3}^{-}$.

\section{ECF volume contraction \\ Vomiting, nasogastric (NG) suction \\ Congenital chloridorrhea $\left(\mathrm{Cl}^{-}-\right.$rich$)$ \\ Villous adenoma}

High volume ileostomy output

Post-hypercapnic state

Thiazide or loop diuretics $\left(\mathrm{U}_{\mathrm{Cl}}{ }^{-}\right.$is variable)

Cystic fibrosis associated with severe perspiration

Bartter syndrome

Gitelman syndrome

\section{ECF volume expansion}

Primary aldosteronism

Renal artery stenosis

Renin-secreting tumors

Glucocorticoid remediable aldosteronism

Cushing's syndrome or disease

Exogenous mineralocorticoids

Congenital adrenal hyperplasia due to 11-beta or 17-alpha hydroxylase deficiency

Licorice (reduced activity of 11-beta hydroxysteroid dehydrogenase )

Liddle syndrome

TABLE 3: Causes of metabolic alkalosis 
Other important causes of metabolic alkalosis in which volume status is variable include, hypokalemia, hypomagnesemia, milk-alkali (calcium-alkali) syndrome (where many patients have reduced GFR limiting $\mathrm{HCO}^{-}$excretion), alkali load especially with reduced GFR, nonreabsorbable anions, such as penicillin and carbenicillin, and refeeding post fasting or starvation [25].

Typical causes of metabolic alkalosis associated with ECF volume contraction are vomiting and NG suction. The gastric $\mathrm{H}^{+}-\mathrm{K}^{+}$ATPase secretes $\mathrm{HCl}$ into the stomach lumen. When $\mathrm{HCl}$ reaches the small bowel, it is neutralized by an equal amount of $\mathrm{HCO}^{-}$secreted into the lumen of the small bowel. The removal of gastric $\mathrm{HCl}$ due to vomiting or nasogastric (NG) suction results in metabolic alkalosis because $\mathrm{HCO}^{-}$is added to the ECF (rather than secreted into the small bowel lumen). $\mathrm{HCO3}^{-}$is subsequently excreted by the kidneys as $\mathrm{NaHCO} 3$, resulting in volume depletion [9]. Metabolic alkalosis is maintained in this case due to volume depletion, secondary aldosteronism, loss of $\mathrm{K}^{+}$(due to secondary aldosteronism and increased distal delivery of NaHCO3). Moreover, hypokalemia shifts $\mathrm{K}+$ extracellularly and subsequently $\mathrm{H}^{+}$(a positive cation) intracellularly [26]. Intracellular acidosis stimulates further $\mathrm{HCO}^{-}$generation. $\mathrm{U}_{\mathrm{Cl}^{-}}$, in this case, is $<20$ mmol/l, while $\mathrm{U}_{\mathrm{Na}^{+}}$can be elevated due to the excretion of $\mathrm{Na}^{+}$with $\mathrm{HCO}^{-}$by the kidneys. Diarrhea usually results in non-anion gap metabolic acidosis. Villous adenoma results in metabolic alkalosis due to loss of $\mathrm{K}^{+}$in stool and volume depletion. Likewise, congenital chloridorrhea also results in metabolic alkalosis. The latter is a rare autosomal recessive disorder due to mutation in the gene SLC26A3 resulting in loss of function of the ileal $\mathrm{HCO}^{-}-\mathrm{Cl}^{-}$exchanger and subsequent $\mathrm{HCO}^{-}$retention [27]. Thiazide and loop diuretics can result in metabolic alkalosis with ECF volume contraction and hypokalemia due to enhanced distal delivery of water and $\mathrm{Na}^{+}$and secondary hyperaldosteronism [28]. $\mathrm{Ucl}^{-}$is variable, it is elevated $(\geqslant 20$ $\mathrm{mmol} / \mathrm{l})$ when diuretics are working and low $(<20 \mathrm{mmol} / \mathrm{l})$ when their effect wears off. Bartter syndrome is due to a loss of function mutation in the TAL resulting in effects similar to the use of a loop diuretic.

Gitelman syndrome is due to loss of function mutation of the $\mathrm{Na}^{+}-\mathrm{Cl}^{-}$cotransporter in the distal collecting duct (DCT) mimicking the effects of a thiazide diuretic [29]. Liddle syndrome is a rare genetic cause of severe hypertension due to gain of function mutation of the epithelial sodium channel (ENaC) resulting in hypokalemia and hyporeninemic hypoaldosteronism [8]. Ucl- is elevated ( $\geqslant 20 \mathrm{mmol} / \mathrm{l})$ in Bartter and Gitelman syndromes. In patients with acute respiratory acidosis, $\mathrm{HCO}^{-}$goes up by $1 \mathrm{mmol} / \mathrm{l}$ for each 10 mmHg increase in $\mathrm{P}_{\mathrm{a}} \mathrm{CO}_{2}$, while in chronic respiratory acidosis, $\mathrm{HCO3}^{-}$goes up by $4 \mathrm{mmol} / \mathrm{l}$ for each 10 mmHg increase in $\mathrm{P}_{\mathrm{a}} \mathrm{CO}_{2}$. For example, a patient with chronic respiratory acidosis and a $\mathrm{P}_{\mathrm{a}} \mathrm{CO}_{2}$ of $70 \mathrm{mmHg}$, is expected to have serum $\mathrm{HCO}^{-}$of $36 \mathrm{mmol} / \mathrm{l}(24+\{4 \times 3\})$ due to metabolic compensation. In the posthypercapnic state, the respiratory acidosis has improved (as in COPD patients who are placed on mechanical ventilation) but the elevation of $\mathrm{HCO3}^{-}$persists, resulting in metabolic alkalosis [30]. Excessive perspiration can cause metabolic alkalosis in patients with cystic fibrosis (CF) [31]. Unexplained metabolic alkalosis with volume depletion and hyponatremia should raise the possibility of cystic fibrosis; this presentation is more common during a heatwave. Aminoglycoside use in patients with CF can result in metabolic alkalosis due to a Bartter-like syndrome. Aminoglycosides activate the calcium-sensing receptor (CaSR), resulting in inhibition of the $\mathrm{Na}^{+}-\mathrm{K}^{+}-2 \mathrm{Cl}^{-}$transporter in the TAL with subsequent increase in urinary $\mathrm{Na}^{+}, \mathrm{K}^{+}, \mathrm{Ca}^{+2}$, and $\mathrm{Mg}^{+2}$ [32-33]. The intact PTH level is low despite hypocalcemia due to the activation of CaSR. A typical cause of metabolic alkalosis associated with ECF volume expansion is primary aldosteronism commonly caused by unilateral aldosterone-secreting adenoma or adrenal hyperplasia. Adrenal carcinoma is rare. Primary aldosteronism manifestations are hypertension, hypokalemia, metabolic alkalosis, and ECF volume expansion [9]. Distal $\mathrm{Na}^{+}$reabsorption is enhanced by aldosterone, resulting in ECF volume expansion. This, in turn, increases $\mathrm{K}^{+}$excretion resulting in hypokalemia. $\mathrm{HCO3}^{-}$generation and retention are increased with hypokalemia as explained above [26]. Metabolic alkalosis is maintained due to autonomous aldosterone secretion. Ucl- in this case is $>20 \mathrm{mmol} / \mathrm{l}$ due to ECF volume expansion [29].

Diagnosis of Metabolic Alkalosis

Metabolic alkalosis is an elevation in blood $\mathrm{pH}$ to $>7.45$. ABGs are required to ascertain the diagnosis of acidbase disorders because high serum $\mathrm{HCO}^{-}$can result from metabolic alkalosis or metabolic compensation for respiratory acidosis. History can identify potential causes of metabolic alkalosis such as vomiting, diuretic use, licorice intake, cystic fibrosis, exogenous sources of $\mathrm{HCO}^{-}$, or primary aldosteronism. Physical examination helps in evaluating ECF volume status. Most clinicians make the diagnosis of metabolic alkalosis in appropriate clinical settings (such as vomiting, NG suction, primary aldosteronism) based on history, physical exam, and basic chemistry profile without doing ABGs. A basic chemistry profile is needed for the diagnosis of metabolic alkalosis. Measurement of other electrolytes (other than serum $\mathrm{HCO}^{-}$), including $\mathrm{Na}^{+}, \mathrm{K}^{+}, \mathrm{Cl}^{-}$, and $\mathrm{Mg}^{+2}$, is critical. Urea and creatinine help in evaluating renal function. Urine electrolytes are obtained. $\mathrm{Ucl}^{-}$is elevated $(\geqslant 20 \mathrm{mmol} / \mathrm{l})$ in case of ECF volume expansion and low $(<20$ $\mathrm{mmol} / \mathrm{l}$ ) in case of ECF volume contraction. Obtaining $\mathrm{Ucl}^{-}$concentration from a random urine sample is adequate and 24-hour urine collection is usually not necessary. Patients suspected of having primary aldosteronism require further testing [34]. Surreptitious diuretic use is an important cause of metabolic 
alkalosis. Varying and parallel levels of $\mathrm{UNa}^{+}$and $\mathrm{Ucl}^{-}$(both are high on some occasions and low on other occasions) raise the possibility of diuretic abuse. Urine diuretic screening is confirmatory. Bartter and Gitelman syndromes require genetic testing to ascertain the diagnosis. The diagnosis of congenital adrenal hyperplasia due to 11-beta or 17-alpha hydroxylase deficiency requires a specialist consultation [35]. Pendred syndrome is an autosomal recessive disorder characterized by deafness and thyroid goiter. It is due to mutations in gene SLC26A4. SLC26A4 encodes for pendrin, which is expressed by the thyroid gland, the inner ears, and the apical membrane of beta-intercalated cells in the cortical collecting duct in the kidneys. Pendred syndrome patients do not have renal abnormalities under basal conditions. They are at risk of developing life-threatening metabolic alkalosis in case of volume depletion or treatment with thiazide diuretics [36]. If a thiazide diuretic is added to acetazolamide, a profound saltwasting ensues because acetazolamide downregulates pendrin [37].

\section{Manifestations of Metabolic Alkalosis}

Most patients with mild to moderate metabolic alkalosis are asymptomatic. Serum $\mathrm{HCO}^{-}$of up to 40 $\mathrm{mmol} / \mathrm{l}$ is tolerated. The manifestations are usually due to concomitant hypokalemia, hypophosphatemia, hypoventilation, volume depletion, and hypocalcemia. Metabolic alkalosis decreases ionized calcium levels [33]. Severe metabolic alkalosis (serum $\mathrm{HCO}^{-}>45 \mathrm{mmol} / \mathrm{l}$ ) can lead to tetany, seizures, cardiac arrhythmias, and delirium [3]. Alkalemia also inhibits respiratory drive and shifts the oxygen-hemoglobin dissociation curve to the left.

Management of Metabolic Alkalosis

In patients with metabolic alkalosis associated with volume contraction ( $\mathrm{Cl}^{-}$-sensitive metabolic alkalosis), it is critical to give isotonic saline $(0.9 \mathrm{NaCl})$ and to replete potassium with potassium chloride orally $(\mathrm{PO})$, intravenously (IV), or both [38]. This strategy will lead to $\mathrm{NaHCO} 3$ diuresis and the restoration of the acidbase balance. $\mathrm{Mg}^{+2}$ should be replaced in patients with hypomagnesemia because hypomagnesemia can result in recalcitrant hypokalemia [38]. Diuretics should be discontinued if feasible; otherwise, the diuretic doses should be reduced. In some patients, such as those with heart failure or liver cirrhosis, discontinuation of diuretics is not an option. In those cases, the addition of a $\mathrm{K}^{+}$sparing diuretic, such as spironolactone, eplerenone, amiloride, or triamterene, may be helpful because it mitigates hypokalemia and hypomagnesemia. Acetazolamide is bicarbonaturic, however, it is very kaliuretic necessitating aggressive $\mathrm{K}+$ monitoring and replacement [28]. It should only be utilized by experienced clinicians. It can be given orally (PO) or intravenously (IV) at a dose of $250-500 \mathrm{mg}$, two to three times daily. The Diabolo study was a double-blind, randomized trial conducted in 15 intensive care units (ICUs) in France [39]. It involved 382 patients with COPD on mechanical ventilation with pure or mixed metabolic alkalosis. Patients in the active arm were given a large dose of acetazolamide (500-1000 mg) twice daily IV. Acetazolamide did not change the primary outcome, which was the reduction in the duration of invasive mechanical ventilation via endotracheal intubation or tracheotomy. There was a statistically significant small reduction in $\mathrm{HCO}^{-}(0.8$ $\mathrm{mmol} / \mathrm{l})$ in the acetazolamide group.

Patients with metabolic alkalosis with ECF volume expansion ( $\mathrm{Cl}^{-}$-resistant metabolic alkalosis) should have their $\mathrm{K}^{+}$replaced as well. The underlying etiology, such as adrenal adenoma, should be the main focus of treatment. Patients with bilateral adrenal hyperplasia are treated with aldosterone blockers such as spironolactone or eplerenone. A low $\mathrm{Na}^{+}$diet is helpful in patients with hyperaldosteronism because it reduces distal $\mathrm{Na}+$ delivery. Peritoneal dialysis or hemodialysis (with a low $\mathrm{HCO}^{-}$in the dialysate $\{30-32$ $\mathrm{mmol} / \mathrm{l}\}$ ) are helpful in correcting metabolic alkalosis in patients with advanced chronic kidney disease (CKD) or who are already on dialysis [40]. Continuous renal replacement therapy (CRRT) is particularly helpful in the management of severe metabolic alkalosis due to the ability to modify electrolytes in replacement solutions and dialysate [3]. Prolonged exposure to inappropriately high dialysate $\mathrm{HCO}^{-}$is associated with increased mortality due to post-dialysis metabolic alkalosis [41]. Currently, $\mathrm{HCO}^{-}$in the dialysate is kept around $35 \mathrm{mmol} /$. Infusion of dilute $\mathrm{HCl}\left(0.1 \mathrm{normal} \mathrm{HCl}, 0.1 \mathrm{~N} \mathrm{HCl}=100 \mathrm{mmol} / 1 \mathrm{H}^{\dagger}\right)$ or ammonium chloride ( $\mathrm{NH} 4 \mathrm{Cl}$ ) is rarely done [42]. $\mathrm{HCl}$ should be placed in a glass container and infused through a central venous catheter; it can cause severe hemolysis and venous thrombosis and should be discontinued once $\mathrm{pH}$ is around 7.50. IV tubing has to be changed every 12 hours. $\mathrm{NH} 4 \mathrm{Cl}$ is metabolized into urea and $\mathrm{HCl}$ and is associated with central nervous system toxicity and gastrointestinal adverse reactions. $\mathrm{NH} 4 \mathrm{Cl}$ can be also given orally. Arginine- $\mathrm{HCl}$ is no longer used because it may cause life-threatening hyperkalemia due to the extracellular shift of $\mathrm{K}^{+}$.

The etiology of metabolic alkalosis should be addressed. Patients with vomiting should be treated symptomatically and the cause of vomiting should be investigated. The use of proton pump inhibitors (PPIs) or $\mathrm{H} 2$ blockers may be helpful in patients with ongoing gastric fluid losses [43]. Exogenous sources of alkali should be identified. Patients should be instructed to avoid licorice or licorice-containing tobacco products. Bartter syndrome is treated with $\mathrm{K}^{+}$repletion, $\mathrm{K}^{+}$-sparing diuretics, such as spironolactone and amiloride, and nonsteroidal anti-inflammatory drugs (NSAIDs) due to their prostaglandin blocking effect [29]. Gitelman 
syndrome is treated in a similar manner in addition to $\mathrm{Mg}^{+2}$ repletion. Blanchard et al. evaluated treatment with indomethacin, eplerenone, or amiloride in 30 patients with Gitelman syndrome [44]. Indomethacin was the most efficacious with a $0.38 \mathrm{mmol} / \mathrm{l}$ increase in plasma $\mathrm{K}^{+}$, followed by amiloride $(0.19 \mathrm{mmol} / \mathrm{increase})$, and then eplerenone $(0.15 \mathrm{mmol} / \mathrm{l})$. Forty percent of patients receiving indomethacin discontinued treatment due to gastrointestinal adverse reactions.

\section{Conclusions}

Metabolic alkalosis is the most common acid-base disorder in hospitalized patients, and it is associated with increased mortality. It is generated by a gain of alkali or loss of acid and is maintained by the failure of the kidneys to excrete excess alkali. Metabolic alkalosis is either associated with volume depletion or volume expansion. Volume depletion metabolic alkalosis is $\mathrm{Cl}^{-}$-sensitive and is treated with isotonic saline solutions and $\mathrm{K}^{+}$replacement while volume expansion metabolic alkalosis is $\mathrm{Cl}^{-}$-insensitive and is treated with $\mathrm{K}^{+}$ repletion and by addressing the underlying cause. Recently, the molecular mechanisms of several genetic disorders associated with metabolic alkalosis have been elucidated such as the Bartter, Gitelman, Liddle, and Pendred syndromes.

\section{Additional Information \\ Disclosures}

Conflicts of interest: In compliance with the ICMJE uniform disclosure form, all authors declare the following: Payment/services info: All authors have declared that no financial support was received from any organization for the submitted work. Financial relationships: All authors have declared that they have no financial relationships at present or within the previous three years with any organizations that might have an interest in the submitted work. Other relationships: All authors have declared that there are no other relationships or activities that could appear to have influenced the submitted work.

\section{References}

1. Lee Hamm L, Nakhoul N, Hering-Smith KS: Acid-base homeostasis. Clin J Am Soc Nephrol. 2015, 10:22322242. 10.2215/CJN.07400715

2. Palmer BF: Normal acid-base balance. Comprehensive Clinical Nephrology. Feehally J, Floege J, Tonelli M, Johnson R (ed): Elsevier Inc, Philadelphia, PA; 2018. 142-148.

3. Segal A, Gennari FJ: Metabolic alkalosis. Comprehensive Clinical Nephrology. Feehally J, Floege J, Tonelli M, Johnson R (ed): Elsevier Inc, Philadelphia, PA; 2018. 160-169.

4. Mountain RD, Heffner JE, Brackett NC, Sahn SA: Acid-base disturbances in acute asthma . Chest. 1990, 98:651-655. 10.1378/chest.98.3.651

5. Narins RG, Emmett M: Simple and mixed acid-base disorders. A practical approach . Medicine. 1980, 59:161187. 10.1097/00005792-198005000-00001

6. Emmett M, Narins RG: Clinical use of the anion gap . Medicine. 1977, 56:38-54. 10.1097/00005792197756010-00002

7. Madias NE, Ayus JC, Adrogué HJ: Increased anion gap in metabolic alkalosis: the role of plasma-protein equivalency. N Engl J Med. 1979, 300:1421-1423. 10.1056/NEJM197906213002507

8. Hamm LL, DuBose TD: Disorders of acid-base balance. Brenner \& Rector's The Kidney. Yu ASL, Chertow G (ed): Elsevier Inc., Philadelphia, PA; 2020. 496-536.

9. Emmett M: Metabolic alkalosis. A brief pathophysiologic review. Clin J Am Soc Nephrol. 2020, 15:18481856. 10.2215/CJN.16041219

10. Holland AE, Wilson JW, Kotsimbos TC, Naughton MT: Metabolic alkalosis contributes to acute hypercapnic respiratory failure in adult cystic fibrosis. Chest. 2003, 124:490-493. 10.1378/chest.124.2.490

11. Berend K: Diagnostic use of base excess in acid-base disorders . N Engl J Med. 2018, 378:1419-1428. 10.1056/nejmra1711860

12. Mæhle K, Haug B, Flaatten H, Nielsen EW: Metabolic alkalosis is the most common acid-base disorder in ICU patients. Crit Care. 2014, 28:420. 10.1186/cc13802

13. Okusawa S, Aikawa N, Abe O: Postoperative metabolic alkalosis following general surgery: Its incidence and possible etiology. Jpn J Surg. 1989, 19:312-318. 10.1007/BF02471407

14. Hodgkin JE, Soeprono FF, Chan DM: Incidence of metabolic alkalemia in hospitalized patients . Crit Care Med. 1980, 8:725-728.

15. Wilson RF, Gibson D, Percinel A, Ali MA, Baker G, LeBlanc LP, Lucas C: Severe alkalosis in critically ill surgical patients. Arch Surg. 1972, 105:193-203. 10.1001/archsurg.1972.04180080051009

16. Anderson LE, Henrich WL: Alkalemia-associated morbidity and mortality in medical and surgical patients . South Med J. 1987, 80:729-733. 10.1097/00007611-198706000-00016

17. Curthoys NP, Moe OW: Proximal tubule function and response to acidosis . Clin J Am Soc Nephrol. 2014, 9:1627-1638. 10.2215/CJN.10391012

18. Wagner CA: Pendrin-a new target for diuretic therapy? . J Am Soc Nephrol. 2016, 27:3499-3501. 10.1681/ASN.2016070720

19. Bruno CM, Valenti M: Acid-base disorders in patients with chronic obstructive pulmonary disease: a pathophysiological review. J Biomed Biotechnol. 2012, 2012:915150. 10.1155/2012/915150

20. Pham TD, Verlander JW, Wang Y, et al.: Aldosterone regulates pendrin and epithelial sodium channel activity through intercalated cell mineralocorticoid receptor-dependent and -independent mechanisms over a wide range in serum potassium. J Am Soc Nephrol. 2020, 31:483-499. 10.1681/ASN.2019050551

21. Seldin DW, Rector FC: The generation and maintenance of metabolic alkalosis. Kidney Int. 1972, 1:306-321. 
10.1038/ki.1972.43

22. Zietse R, Zoutendijk R, Hoorn EJ: Fluid, electrolyte and acid-base disorders associated with antibiotic therapy. Nat Rev Nephrol. 2009, 5:193-202. 10.1038/nrneph.2009.17

23. Durkalec-Michalski K, Zawieja EE, Podgórski T, Loniewski I, Zawieja BE, Warzybok M, Jeszka J: The effect of chronic progressive-dose sodium bicarbonate ingestion on CrossFit-like performance: a double-blind, randomized cross-over trial. PLoS One. 2018, 13:0197480. 10.1371/journal.pone.0197480

24. Krustrup P, Ermidis G, Mohr M: Sodium bicarbonate intake improves high-intensity intermittent exercise performance in trained young men. J Int Soc Sports Nutr. 2015, 12 :25. 10.1186/s12970-015-0087-6

25. Emmett M: Diagnosis of simple and mixed disorders . Acid-Base and Electrolyte Disorders A Companion to Brenner \& Rector's The Kidney. DuBose TD, Hamm LL (ed): Elsevier Inc, Philadelphia, PA; 2002. 41-53.

26. Aronson PS, Giebisch G: Effects of pH on potassium: new explanations for old observations. J Am Soc Nephrol. 2011, 22:1981-1989. 10.1681/ASN.2011040414

27. Höglund P, Haila S, Socha J, et al.: Mutations of the down-regulated in adenoma (DRA) gene cause congenital chloride diarrhoea. Nat Genet. 1996, 14:316-319. 10.1038/ng1196-316

28. Ellison DH: Clinical pharmacology in diuretic use. Clin J Am Soc Nephrol. 2019, 14:1248-1257. 10.2215/CJN.09630818

29. Fulchiero R, Seo-Mayer P: Bartter syndrome and Gitelman syndrome. Pediatr Clin North Am. 2019, 66:121134. 10.1016/j.pcl.2018.08.010

30. Banga A, Khilnani GC: Post-hypercapnic alkalosis is associated with ventilator dependence and increased ICU stay. COPD J Chronic Obstr Pulm Dis. 2009, 6:437-440. 10.3109/15412550903341448

31. Fustik S, Pop-Jordanova N, Slaveska N, Koceva S, Efremov G: Metabolic alkalosis with hypoelectrolytemia in infants with cystic fibrosis. Pediatr Int. 2002, 44:289-292. 10.1046/j.1442-200X.2002.01563.x

32. Chou CL, Chen YH, Chau T, Lin SH: Acquired Bartter-like syndrome associated with gentamicin administration. Am J Med Sci. 2005, 329:144-149. 10.1097/00000441-200503000-00007

33. Tinawi M: Disorders of calcium metabolism: hypocalcemia and hypercalcemia. Cureus. 2021, 13:e12420. 10.7759/cureus. 12420

34. Funder JW, Carey RM, Mantero F, et al.: The management of primary aldosteronism: case detection, diagnosis, and treatment: an endocrine society clinical practice guideline. J Clin Endocrinol Metab. 2016, 101:1889-1916. 10.1210/jc.2015-4061

35. Witchel SF: Congenital adrenal hyperplasia. J Pediatr Adolesc Gynecol. 2017, 30:520-534. 10.1016/j.jpag.2017.04.001

36. Kandasamy N, Fugazzola L, Evans M, Chatterjee K, Karet F: Life-threatening metabolic alkalosis in Pendred syndrome. Eur J Endocrinol. 2011, 165:167-170. 10.1530/EJE-11-0101

37. Zahedi K, Barone S, Xu J, Soleimani M: Potentiation of the effect of thiazide derivatives by carbonic anhydrase inhibitors: Molecular mechanisms and potential clinical implications. PLoS One. 2013, 8:79327. 10.1371/journal.pone.0079327

38. Tinawi M: Hypokalemia: a practical approach to diagnosis and treatment. Arch Clin Biomed Res. 2020, 4:4866. 10.26502/acbr.50170088

39. Faisy C, Meziani F, Planquette B, et al.: Effect of acetazolamide vs placebo on duration of invasive mechanical ventilation among patients with chronic obstructive pulmonary disease. A randomized clinical trial. JAMA. 2016, 315:480-488. 10.1001/jama.2016.0019

40. Abramowitz MK: Bicarbonate balance and prescription in ESRD . J Am Soc Nephrol. 2017, 28:726-734. 10.1681/ASN.2016070780

41. Tentori F, Karaboyas A, Robinson BM, et al.: Association of dialysate bicarbonate concentration with mortality in the Dialysis Outcomes and Practice Patterns Study (DOPPS). Am J Kidney Dis. 2013, 62:738746. 10.1053/j.ajkd.2013.03.035

42. Brimioulle S, Berre J, Dufaye P, Vincent JL, Degaute JP, Kahn RJ: Hydrochloric acid infusion for treatment of metabolic alkalosis associated with respiratory acidosis. Crit Care Med. 1989, 17:232-236. 10.1097/00003246-198903000-00006

43. Eiro M, Katoh T, Watanabe T: Use of a proton-pump inhibitor for metabolic disturbances associated with anorexia nervosa. N Engl J Med. 2002, 347:373-374. 10.1056/nejm200208013470520

44. Blanchard A, Vargas-Poussou R, Vallet M, et al.: Indomethacin, amiloride, or eplerenone for treating hypokalemia in Gitelman syndrome. J Am Soc Nephrol. 2015, 26:468-475. 10.1681/ASN.2014030293 